\title{
Alveolar macrophages of GM-CSF knockout mice exhibit mixed M1 and M2 phenotypes
}

\author{
Heidi Dalrymple', Barbara P Barna', Anagha Malur ${ }^{1}$, Achut G Malur², Mani S Kavuru and Mary Jane Thomassen ${ }^{1 *}$
}

\begin{abstract}
Background: Activin A is a pleiotrophic regulatory cytokine, the ablation of which is neonatal lethal. Healthy human alveolar macrophages (AMs) constitutively express activin A, but AMs of patients with pulmonary alveolar proteinosis (PAP) are deficient in activin A. PAP is an autoimmune lung disease characterized by neutralizing autoantibodies to Granulocyte-Macrophage Colony Stimulating Factor (GM-CSF). Activin A can be stimulated, however, by GM-CSF treatment of AMs in vitro. To further explore pulmonary activin A regulation, we examined AMs in bronchoalveolar lavage (BAL) from wild-type C57BL/6 compared to GM-CSF knockout mice which exhibit a PAP-like histopathology. Both human PAP and mouse GM-CSF knockout AMs are deficient in the transcription factor, peroxisome proliferator activated receptor gamma (PPARY).

Results: In sharp contrast to human PAP, activin A mRNA was elevated in mouse GM-CSF knockout AMs, and activin A protein was increased in BAL fluid. Investigation of potential causative factors for activin A upregulation revealed intrinsic overexpression of IFNY, a potent inducer of the M1 macrophage phenotype, in GM-CSF knockout BAL cells. IFNy mRNA was not elevated in PAP BAL cells. In vitro studies confirmed that IFNy stimulated activin A in wild-type AMs while antibody to IFNy reduced activin A in GM-CSF knockout AMs. Both IFNy and Activin A were also reduced in GM-CSF knockout mice in vivo after intratracheal instillation of lentivirus-PPARy compared to control lentivirus vector. Examination of other M1 markers in GM-CSF knockout mice indicated intrinsic elevation of the IFNy-regulated gene, inducible Nitrogen Oxide Synthetase (iNOS), CCL5, and interleukin (IL)-6 compared to wildtype. The M2 markers, IL-10 and CCL2 were also intrinsically elevated.
\end{abstract}

Conclusions: Data point to IFNY as the primary upregulator of activin A in GM-CSF knockout mice which in addition, exhibit a unique mix of M1-M2 macrophage phenotypes.

Keywords: Interferon gamma, Activin A, Alveolar macrophages

\section{Background}

Activin A, a pleiotrophic cytokine belonging to the transforming growth factor-beta (TGF- $\beta$ ) superfamily, is synthesized by many cell types throughout the body $[1,2]$. The molecular structure is a disulphide-linked, homodimeric glycoprotein composed of two inhibin $\beta A$ chains. Activin A was first recognized as an endocrine factor, but is now known to be essential to developmental and repair processes, and total ablation is neonatal lethal [3]. Contrasting regulatory roles have been cited for Activin A in inflammation [4]. Human monocytes

\footnotetext{
* Correspondence: thomassenm@ecu.edu

'Program in Lung Cell Biology and Translational Research, Division of Pulmonary, Critical Care Medicine and Sleep Medicine, East Carolina University, Brody School of Medicine, 3E-149 Brody Medical Sciences Building, Greenville, NC 27834, USA

Full list of author information is available at the end of the article
}

synthesize activin A upon stimulation with classical M1 macrophage activation inducers such as GM-CSF, LPS, and IFN $\gamma[5,6]$. Exposure of GM-CSF treated macrophages to anti-Activin A reduces M1 markers and enhances alternative M2 phenotype markers such as IL10 [7]. Activin A also inhibits monocyte production of IL-1 $\beta$ and enhances IL-1 receptor antagonist production [8]. Interestingly, in severe asthma, activin A may be elevated in serum, and data from animal models suggests that activin A may suppress T helper 2 (Th2) mediated allergic responses [9]. Collectively these observations suggest multifunctional roles for activin A in inflammatory processes.

Maintenance of lung homeostasis is a complex process dependent upon a network of interacting cells and cytokines. GM-CSF is required for alveolar macrophage 
(AM) function and pulmonary homeostasis [10]. In genetically altered mice homozygous for a disrupted GM-CSF gene (GM-CSF knockout), hematopoiesis is normal but there is accumulation of excess lung surfactant $[11,12]$. This surfactant pathology mirrors that of human PAP, an autoimmune disease characterized by high levels of autoantibody to GM-CSF [12-14]. Aerosolized GM-CSF resolves the pulmonary pathology of GMCSF knockout mice, thus demonstrating that surfactant homeostasis can be influenced by local administration of GM-CSF to the respiratory tract [15].

Previously we reported that healthy human AMs synthesize activin A in response to GM-CSF but AMs of patients with PAP are deficient in activin A [16]. In addition, PAP AMs are deficient in the nuclear transcription factor, Peroxisome Proliferator-activated Receptor, (PPAR $\gamma$ ), a regulator of lipid and glucose metabolism that is restored by GM-CSF treatment [17]. PPAR $\gamma$ has also been shown to be a negative regulator of inflammation $[18,19]$. Interestingly, alveolar macrophages of GM-CSF knockout mice are also deficient in PPARy [20]. The role of activin A in the lung has not been established. Because of the phenotypic similarities between human PAP and the GM-CSF knockout mouse, this study was undertaken to investigate activin A regulation in the lung. Initially, it was hypothesized that activin A might be impaired in GM-CSF knockout mice based upon previous data from PAP studies [16].

\section{Results}

Activin A and IFNY are intrinsically elevated in GM-CSF knockout mice as compared to wild-type mice

Unlike previous findings of activin A deficiency in human PAP [16], activin A mRNA expression of BAL cells was significantly $(\mathrm{p}<0.005)$ elevated in GM-CSF knockout mice compared to wild-type controls (Figure 1A). Quantification of activin A protein in BAL fluids confirmed mRNA findings with significantly $(\mathrm{p}<0.05)$ elevated protein levels in GM-CSF knockout compared to wild-type (Figure 1B). GM-CSF knockout expression

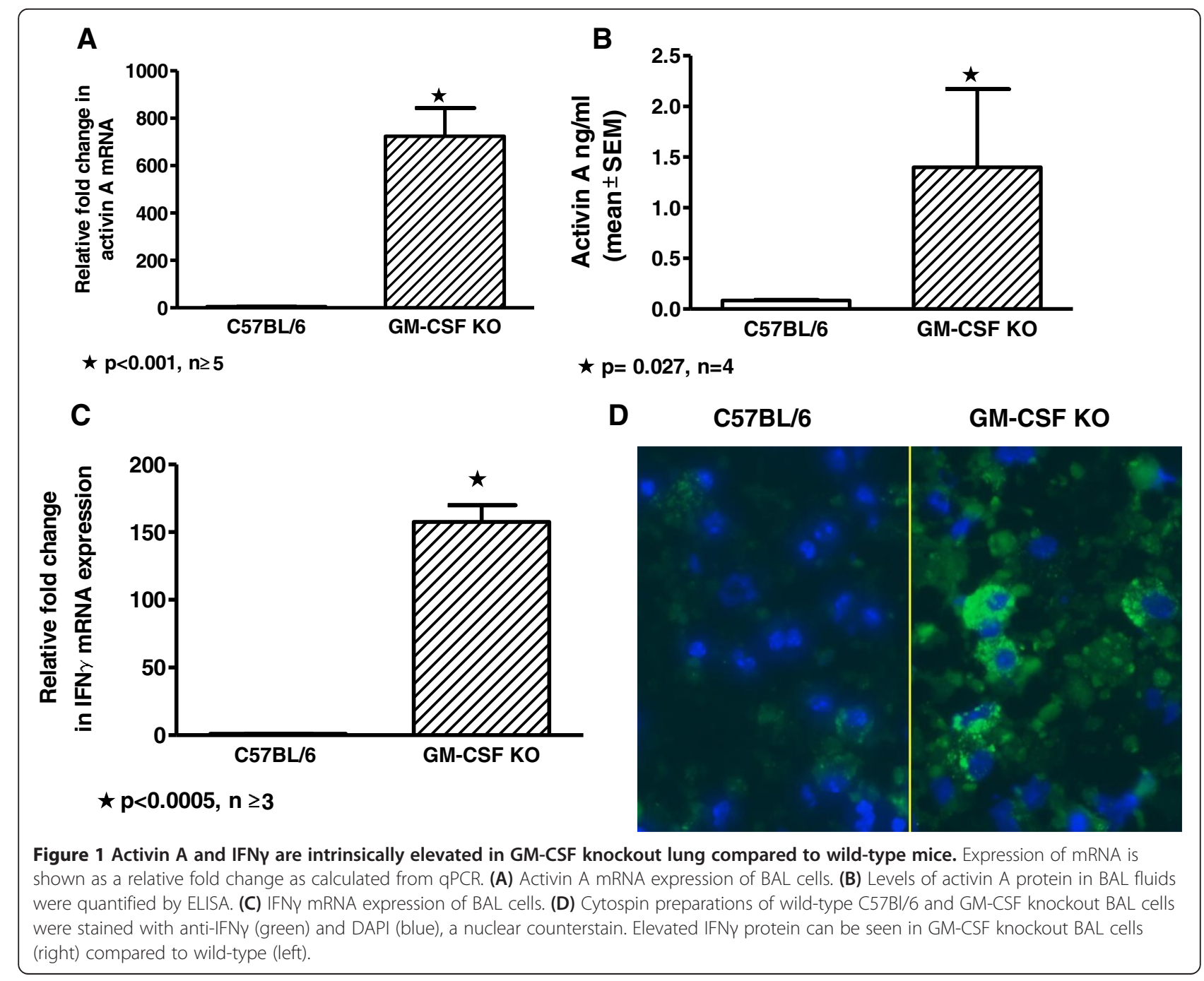


of follistatin, an inhibitor of activin A [21], was similar to wild-type mice (data not shown) and thus could not account for the striking elevation of activin A.

Intrinsic factors that could potentially affect activin A levels were subsequently investigated in GM-CSF knockout mice. Macrophage colony-stimulating factor (M-CSF) has been reported to be upregulated in GMCSF knockout mice [22]. Examination of M-CSF in the current study, however, indicated no effect on activin A in vitro in either wild-type or GM-CSF knockout AMs (data not shown). Elevated IFN $\gamma$ has been reported in lungs of GM-CSF knockout mice [23] therefore intrinsic levels of IFNY were examined. IFN $\gamma$ mRNA expression was significantly $(\mathrm{p}<0.005)$ elevated in GM-CSF knockout BAL cells compared to wild-type controls (Figure 1C). Immunocytochemistry of GM-CSF knockout BAL cells confirmed mRNA results and indicated markedly increased expression of intracellular IFNY protein compared to wild-type (Figure 1D).

IFN $\gamma$ is not elevated in human PAP BAL cells In contrast to results from GM-CSF knockout mice, examination of IFN $\gamma$ expression in human BAL cells from PAP patients revealed no significant increase compared to healthy controls (Figure 2).

\section{Activin A levels are enhanced by IFN $\gamma$ and reduced by IFNץ blockade}

IFN $\gamma$ has been shown to upregulate activin A expression in human monocytes [5] but AMs have not been studied. Results from 24-hour in vitro cultures of wild-type AMs indicated that IFN $\gamma(100 \mathrm{U} / \mathrm{ml})$ significantly $(\mathrm{p}<0.05)$ increased activin A expression (Figure 3A). To determine

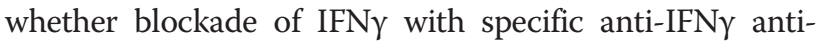
body would alter intrinsic activin A expression, unstimulated GM-CSF knockout AMs were cultured in vitro for 24 hours with irrelevant immunoglobulin (Ig) or antiIFN $\gamma$. ELISA analysis of conditioned media indicated that

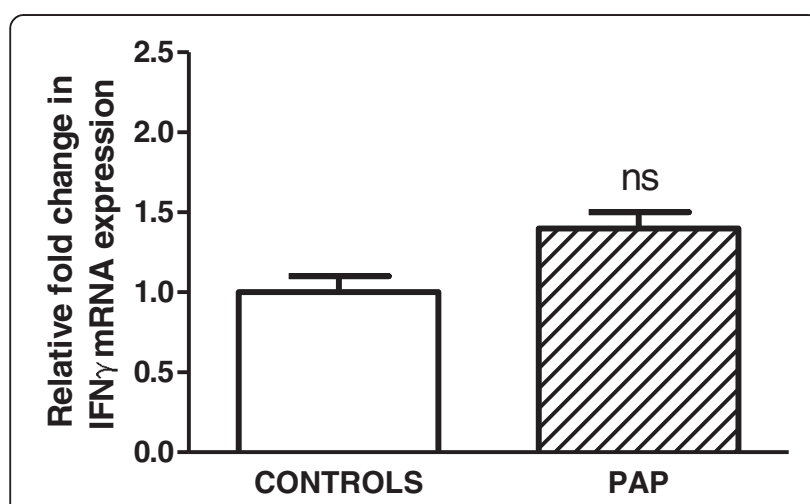

Figure 2 Expression of IFNy is not detectable in BAL cells from human PAP patients. Expression of IFNy mRNA in PAP patients $(n=6)$ did not significantly differ from that of healthy controls $(n=5)$.

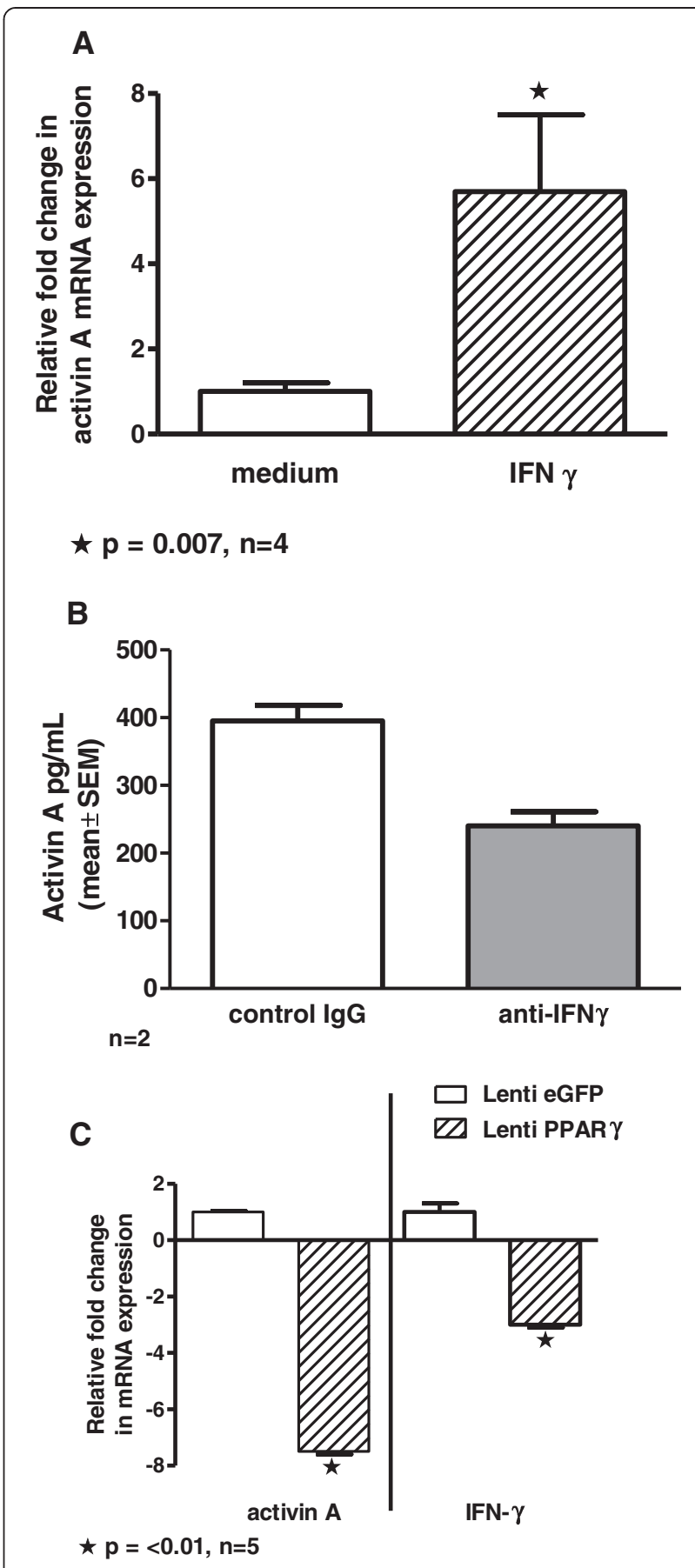

Figure 3 Activin A levels are increased by IFN $\gamma$ and reduced by IFN $\gamma$ blockade. (A) IFNY upregulates activin A mRNA in wild-type alveolar macrophages cultured for 24 hours with IFNY (100 U/ml) $[n=4]$. (B) Antibody to IFNy represses intrinsic activin A synthesis in GM-CSF knockout alveolar macrophages. GM-CSF knockout alveolar macrophages were cultured with irrelevant IgG or anti-IFNy for 24 hours and activin A was determined in conditioned media by ELISA $(n=2)$. (C) BAL cells from GM-CSF knockout mice receiving intratracheal instillation of lentivirus-PPARy or control lentivirus-EGFP were analyzed for IFNy and activin A mRNA expression at 10 days post-transduction $(n=5)$. 
anti-IFN $\gamma$ reduced activin A protein synthesis compared to irrelevant Ig (Figure 3B) confirming that IFNy blockade reduced intrinsic activin A production.

Because activin A is intrinsically elevated in PPAR $\gamma$ deficient GM-CSF knockout mice but severely decreased in PPAR $\gamma$ deficient human PAP patients [16], it appeared unlikely that PPAR $\gamma$ would exert a direct effect on activin A. Observations made elsewhere [24] also found no evidence of a PPAR $\gamma$ effect on activin A. We have shown, however, that IFN $\gamma$ is elevated in macrophagespecific PPAR $\gamma$ knockout mice and significantly reduced after in vivo restoration of PPAR $\gamma$ via a lentivirus vector [25]. We utilized this approach to determine whether PPAR $\gamma$ restoration in GM-CSF knockout mice might reduce IFN $\gamma$ and thereby reduce activin A. Results supported this action. Ten days post intratracheal inoculation of lentivirus reagents into GM-CSF knockout mice, BAL cell mRNA expression of both IFN $\gamma$ and activin A was significantly reduced in animals receiving lentivirusPPAR $\gamma$ compared to controls receiving lentivirus-eGFP $(\mathrm{p}<0.05)$ (Figure $3 \mathrm{C})$.

Human alveolar macrophage activin A is increased by IFN $\gamma$ While the above studies clearly defined IFN $\gamma$-mediated regulation of activin $\mathrm{A}$ in murine alveolar macrophages, it was necessary to confirm this pathway in human alveolar macrophages. In vitro studies demonstrated that IFN $\gamma$ significantly enhanced activin A protein production (Figure 4) in healthy human alveolar macrophages. Thus activin A synthesis in both human and murine alveolar macrophages is responsive to IFN $\gamma$ upregulation even though intrinsic activin A levels differ between human and mouse.

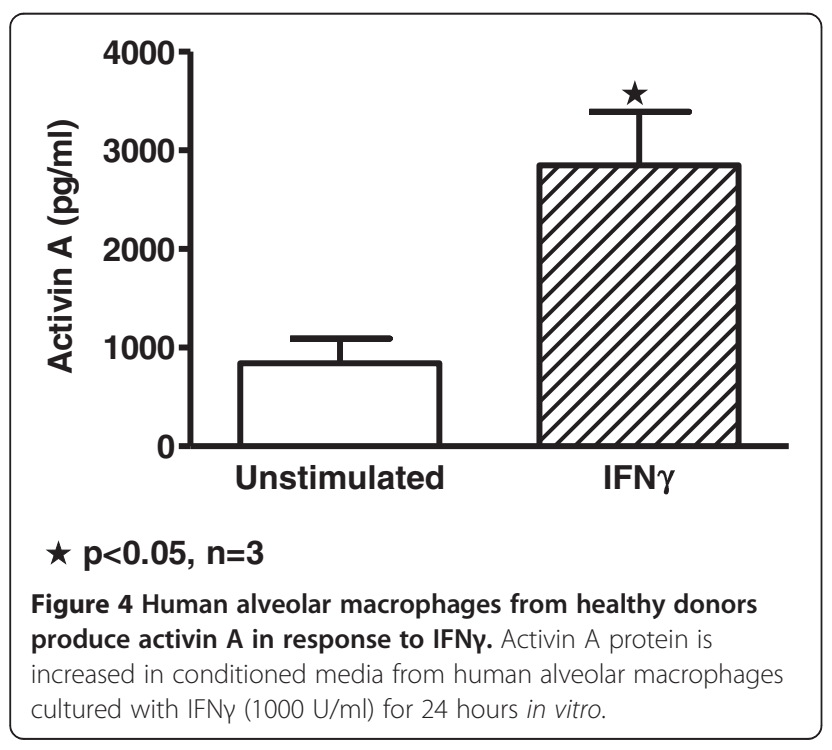

GM-CSF BAL cells show intrinsic elevation of both M1 and M2 macrophage phenotypic markers

We and others reported previously that M-CSF gene expression and protein, a cytokine associated with the M2 macrophage phenotype, was elevated in GM-CSF knockout mice $[22,26]$. Current data indicate that the M1-associated cytokine, IFNy (protein and gene expression) is also increased in these mice. Therefore, it was unclear whether GM-CSF knockout BAL cells would express predominantly M1 or M2 profiles. To address this issue, we determined mRNA expression of several M1 and M2 markers in GM-CSF knockout BAL cells. With respect to $\mathrm{M} 1$ markers, we examined the IFN $\gamma$ regulated target gene, iNOS (Figure 5A), together with CCL5 (Figure 5B), and IL-6 (Figure 5C), and found that all were significantly elevated compared to wild-type mice. The M2 marker, IL-10, has been reported to be suppressed by elevated activin A [7,27], and in PAP, activin A deficiency is accompanied by elevated IL-10 $[16,28,29]$. Surprisingly, analysis of IL-10 expression in GM-CSF knockout BAL cells revealed significantly elevated levels compared to wild-type mice (Figure 5D). Analysis of another M2-associated marker, CCL2, also indicated significant elevation compared to wild-type mice (Figure 5E). These results suggested that GM-CSF knockout alveolar macrophages might constitute a mixed population of both M1 and M2 phenotypes.

\section{Discussion}

The current findings suggest that IFN $\gamma$ is a major contributory factor to the intrinsic elevation of activin A in AMs. Findings also point out a striking difference in activin A expression in human PAP and GM-CSF knockout mice despite common deficiencies of GM-CSF and PPAR $\gamma$ (summarized in Table 1). In parallel with activin A, GM-CSF knockout mice displayed over-expression of IFNy [23], a positive regulator of activin A [5]. In contrast, BAL cells of PAP patients do not exhibit elevated IFN $\gamma$ and activin A is deficient [16].

Elevated IFNy has been reported previously in the BAL fluids of GM-CSF knockout mice [23]. Our previous studies also found elevated IFNy expression in macrophage-specific PPAR $\gamma$ knockout mice [25]. Restoration of PPAR $\gamma$ via lentivirus vector in these mice greatly diminished IFN $\gamma$ expression [25]. In the current study, similar results were seen after PPAR $\gamma$-lentivirus treatment of GM-CSF knockout mice. Such findings suggest that the PPARy deficiency present in GM-CSF knockout mice may contribute to elevated IFNץ. GM-CSF has been shown to be a critical upregulator of PPAR $\gamma$ $[31,34]$. The total lack of GM-CSF in knockout mice may maintain an extreme PPARy deficiency which is ineffective at repressing inflammatory mediators such as IFN $\gamma$. In human PAP, IFN $\gamma$ levels are not increased 


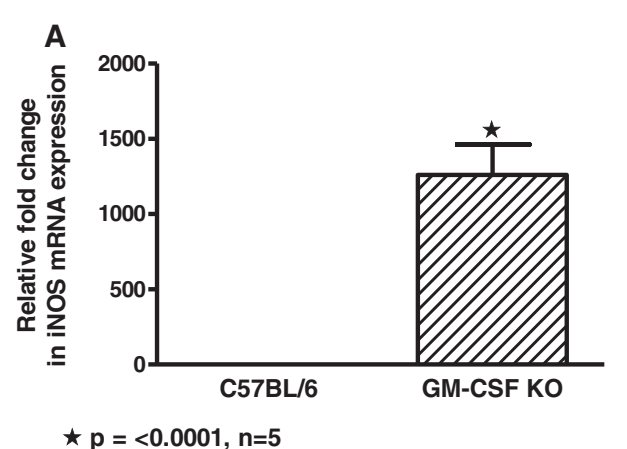

B

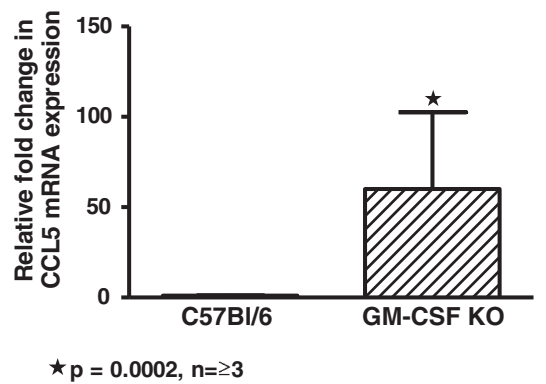

D
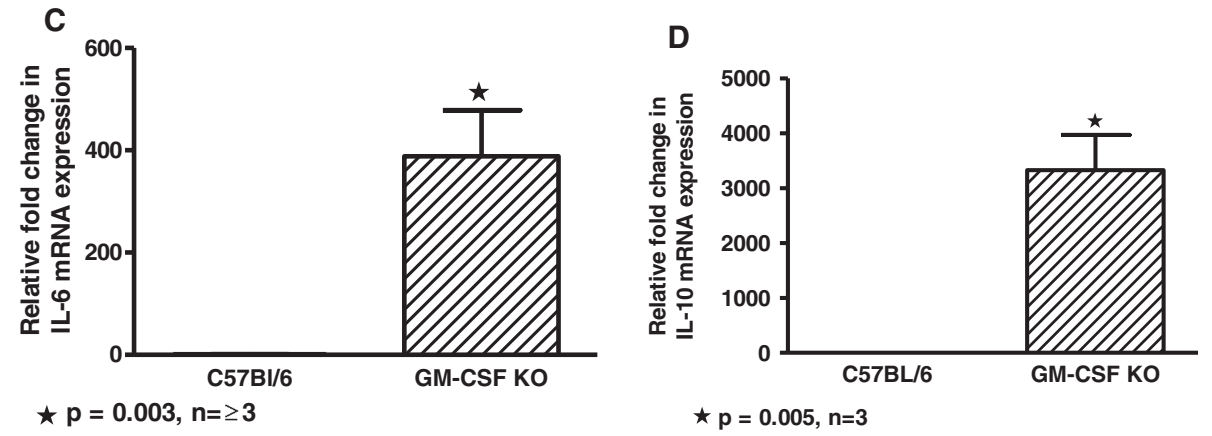

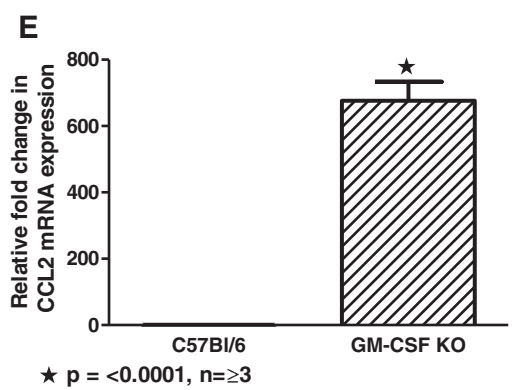

Figure 5 mRNA expression of both M1 and M2 macrophage phenotypic markers is intrinsically elevated in GM-CSF knockout BAL cells compared to wild-type mice. Elevated mRNA expression of M1 markers: (A) iNOS; (B) CCL5, and (C) IL-6. Elevated mRNA expression of M2 markers: (D) IL-10, and (E) CCL2.

despite PPAR $\gamma$ deficiency, furthermore, GM-CSF is not totally absent [29]. The primary etiology of PAP is considered to be an autoimmune response to GM-CSF in the form of high levels of circulating, neutralizing autoantibody to GM-CSF [13]. It is also possible that additional regulatory mechanisms are present in human lung to help prevent IFNY buildup in PAP.

The varying characteristics of activated macrophages have led to attempts to categorize activation phenotypes [35-39]. The M1 phenotype is characterized by production of microbial or IFN $\gamma$-triggered molecules such as iNOS and IL-12. GM-CSF has been cited as an inducer of M1 phenotypes while M-CSF has been shown to induce the M2 alternative activation phenotype in which IL-10 or TGF $\beta$ may be produced $[7,40]$. We have shown that M-CSF is elevated in GM-CSF knockout mice [22] and in human PAP [33] which might suggest the presence of an M2 macrophage phenotype (see Table 1). Interestingly, PPAR $\gamma$, which is deficient in GM-CSF knockout mice, is also a major driver of the M2 phenotype [41]. It has been pointed out however, that macrophage phenotypes were defined by carefully controlled in vitro conditions which may be vastly different from the in vivo milieu [42]. Thus the juxtaposition of both IFNY and M-CSF in the lungs of GM-CSF knockout mice could produce the novel combination of macrophage activation phenotypes illustrated by elevated M1 (iNOS, CCL5, IL-6) and M2 (IL-10, CCL2) markers (Table 1). Other IFNYinducible pro-inflammatory mediators (chemokines CXCL9, CXCL10, and CXCL11) have been noted in the lungs of GM-CSF knockout mice [23]. Previously, we found that MMP-2, a matrix metalloproteinase associated with M-CSF and alternative M2 activation, is also elevated in GM-CSF knockout BAL cells [33]. 
Table 1 Summary: comparison of macrophage activation regulatory factors in human pulmonary alveolar proteinosis (PAP) patients and GM-CSF knockout mice

\begin{tabular}{cccc}
\hline Regulatory factors & Associated macrophage phenotype & PAP patients & GM-CSF knockout mice \\
\hline GM-CSF & M1 & Deficient protein, not mRNA [28] & Absent [11] \\
Activin A & M1 & Deficient [16] & Elevated \\
IL-6 & M1 & Not done & Elevated \\
CCL5 & M1 & Not done & Elevated \\
IFNY & M1 & mRNA - not elevated (comparable to healthy controls) & Elevated [23] \\
INOS & M1 & Undetectable in human alveolar macrophages & Elevated \\
M-CSF & (unpublished observation) & Elevated [22] \\
PPARY & M2 & Elevated [30] & Deficient [31] \\
CCL2 & M2 & Deficient [31] & Elevated \\
IL-10 & M2 & Elevated [32] & Elevated \\
MMP2 & M2 & Elevated [29] & Elevated [33] \\
\hline
\end{tabular}

\section{Conclusions}

The current findings extend our previous studies examining pulmonary mechanisms operative in human PAP and the GM-CSF knockout mouse. It is clear that pathways of activin A regulation may utilize GM-CSF or IFN $\gamma$ as stimulatory factors. In the GM-CSF knockout mouse, lack of GM-CSF may restrict production of sufficient PPAR $\gamma$ to control inflammation. The persistent elevation of both M-CSF and IFN $\gamma$ may influence AMs to express characteristics of both M1 and M2 phenotypes. The current data emphasize the plasticity of alveolar macrophages in assuming a unique activation phenotype when regulatory pathways become dysfunctional.

\section{Methods}

Mice

Animal studies were conducted in conformity with Public Health Service (PHS) Policy on humane care and use of laboratory animals and were approved by the institutional animal care committee. The GM-CSF knockout mice were generated by Dr. Glenn Dranoff and have been previously described [11]. Controls consisted of C57BL/6 wild type mice obtained from Jackson Laboratory (Bar Harbor, ME). BAL cells and fluids were obtained from 8-12 week-old GM-CSF knockout mice and age and gender matched wild-type C57BL/6 controls as previously described [43]. Briefly, cytospins of BAL cells were stained with a modified Wright-Giemsa stain for differentials. A minimum of 100 cells was scored for each lavage. Mean ( \pm SEM) BAL cells from C57BL/6 mice were composed of $98 \pm 1 \%$ macrophages and $2 \pm$ $1 \%$ lymphocytes; GM-CSF knockout BAL cells were composed of $91 \pm 2 \%$ macrophages and $5 \pm 1 \%$ lymphocytes. For in vitro studies, BAL cells were plated at 150,000 cells/well in 48-well plates as previously described [25]. Recombinant murine IFN $\gamma$ was obtained from
R\&D Systems. Neutralizing anti-IFNy and control antibodies were purchased from BD Biosciences. For all experiments a minimum of 3 sets of pooled BAL cells from 3-5 mice were used except where indicated.

\section{Human subjects}

The protocol was approved by the East Carolina University Institutional Review Board and written informed consent was obtained from all patients and control subjects. Healthy control subjects had no history of lung disease and were not on medication. PAP subjects were recruited from patients undergoing routine clinical evaluation. The diagnosis of idiopathic PAP was confirmed by histopathological examination of material from open lung or transbronchial biopsies as previously described [29]. Alveolar macrophages were derived from bronchoalveolar lavage (BAL) obtained by fiberoptic bronchoscopy as previously described [29]. Differential cell counts were obtained from cytospins stained with a modified Wright's stain. For PAP patients, the mean BAL cell percentages (means \pm SEMs) were: alveolar macrophages, $83 \pm 9 \%$, and lymphocytes, $10 \pm 5 \%$. Healthy control values were: alveolar macrophages, $93 \pm 2 \%$ and lymphocytes, $7 \pm 2 \%$. For in vitro culture, BAL cells were plated into 24-well plates (300,000 alveolar macrophages per well) or chamber slides (60,000 cells/well) as previously described [16].

\section{RNA purification and analysis}

Total RNA was extracted from BAL cells or cultured alveolar macrophages and analyzed by Q-PCR as previously described [25]. RNA specimens were analyzed in duplicate using primer-probe sets for activin A, IL-10, iNOS, CCL2, CCL5, IL-6, IFN $\gamma$ and GAPDH as previously described [25]. Data were normalized to GAPDH and expressed as fold change in mRNA expression compared to controls values as previously described [44]. 


\section{Lentivirus plasmid and transduction}

The self-inactivating lentivirus expression vector used here has been described previously [45]. Construction of the lentivirus-PPARY (lenti-PPARY) and control lentivirus construct has also been described in detail $[20,25]$. Control consisted of a lentivirus vector expressing Enhanced Green Fluorescent Protein (eGFP) (lenti-EGFP). Animals received $50 \mathrm{ug}$ of lentivirus vector in $50 \mu \mathrm{l}$ PBS or PBS alone (sham) by intratracheal instillation. After 10 days, five animals per group were lavaged, BAL differential counts were obtained and RNA was extracted.

\section{Activin $\mathrm{A}$ and follistatin protein assays}

Activin A or follistatin proteins ( $\mathrm{pg} / \mathrm{ml}$ ) in BAL fluids or conditioned media from cultured alveolar macrophages were quantified by ELISA according to the manufacturer's instructions (Serotec, Raleigh, NC; R\&D Systems, Minneapolis, MN).

\section{Immunocytochemistry}

Immunocytochemistry for IFN $\gamma$ was carried out on cytospin samples from freshly isolated BAL cells using rat anti-mouse IFNY (Santa Cruz Biotechnology,1:100) followed by goat anti-rat IgG (Invitrogen) as described [25]. Slides were counter-stained with DAPI (Invitrogen) to allow nuclear localization.

\section{Statistics}

Data were analyzed by student's t-test using Prism software (GraphPad). Values from treated cells were compared to untreated. Significance was defined as $\mathrm{p} \leq 0.05$.

\section{Abbreviations}

AM: Alveolar macrophage; GM-CSF: Granulocyte macrophage colony stimulating factor; PAP: Pulmonary alveolar proteinosis; BAL: Bronchoalveolar lavage; PPARY: Peroxisome proliferator activated receptor; IFNy: Interferony; iNOS: Inducible nitric oxide synthetase.

\section{Competing interests}

The authors declare that they have no competing interests.

\section{Authors' contributions}

HD contributed to acquisition of the data, analysis and interpretation of data, drafting of the manuscript and final approval of the version to be published; BPB contributed to the design, analysis and interpretation of data, drafting of the manuscript and final approval of the version to be published; AM contributed to the conception and design, acquisition of the data, analysis and interpretation of data and final approval of the version to be published; AGM contributed to acquisition of the data and final approval of the version to be published; MSK contributed to the acquisition of data and final approval of the version to be published; MJT contributed to the conception and design, acquisition of data, analysis and interpretation of data, drafting of the manuscript and final approval of the version to be published. All authors read and approved the final manuscript.

\section{Acknowledgements}

This work was funded by North Carolina Biotechnology Center FRG-1013 and $\mathrm{NIH} \mathrm{RO1} \mathrm{Al164153} \mathrm{to} \mathrm{MJT.}$

\section{Author details}

'Program in Lung Cell Biology and Translational Research, Division of Pulmonary, Critical Care Medicine and Sleep Medicine, East Carolina University, Brody School of Medicine, 3E-149 Brody Medical Sciences Building, Greenville, NC 27834, USA. ${ }^{2}$ Department of Microbiology and Immunology, East Carolina University, Greenville, NC, USA.

Received: 11 April 2013 Accepted: 29 August 2013

Published: 17 September 2013

\section{References}

1. Vale W, Rivier J, Vaughan J, McClintock R, Corrigan A, Woo W, et al: Purification and characterization of an FSH releasing protein from porcine ovarian follicular fluid. Nature 1986, 321:776-779.

2. Ling $N$, Ying $S Y$, Ueno N, Shimasaki S, Esch F, Hotta M, et al: Pituitary FSH is released by a heterodimer of the beta-subunits from the two forms of inhibin. Nature 1986, 321:779-782.

3. Matzuk MM, Kumar TR, Vassalli A, Bickenbach JR, Roop DR, Jaenisch R, et al: Functional analysis of activins during mammalian development. Nature 1995, 374:354-356.

4. De Kretser DM, O'Hehir RE, Hardy CL, Hedger MP: The roles of activin A and its binding protein, follistatin, in inflammation and tissue repair. Mol Cell Endocrinol 2012, 359:101-106.

5. Shao L, Frigon NL Jr, Sehy DW, Yu AL, Lofgren J, Schwall R, et al: Regulation of production of activin A in human marrow stromal cells and monocytes. Exp Hematol 1992, 20:1235-1242.

6. Abe M, Shintani Y, Eto Y, Harada K, Kosaka M, Matsumoto T: Potent induction of activin $\mathrm{A}$ secretion from monocytes and bone marrow stromal fibroblasts by cognate interaction with activated T cells. J Leukoc Biol 2002, 72:347-352.

7. Lacey DC, Achuthan A, Fleetwood AJ, Dinh H, Roiniotis J, Scholz GM, et al: Defining GM-CSF-and macrophage-CSF-dependent macrophage responses by in vitro models. J Immunol 2012, 188:5752-5765.

8. Ohguchi M, Yamato K, Ishihara Y, Koide M, Ueda N, Okahashi N, et al: Activin $\mathrm{A}$ regulates the production of mature interleukin- 1 beta and interleukin-1 receptor antagonist in human monocytic cells. $J$ Interferon Cytokine Res 1998, 18:491-498.

9. Karagiannidis C, Hense G, Martin C, Epstein M, Ruckert B, Mantel PY, et al: Activin $A$ is an acute allergen-responsive cytokine and provides a link to TGF-beta-mediated airway remodeling in asthma. J Allergy Clin Immunol 2006, 117:111-118.

10. Trapnell BC, Whitsett JA: GM-CSF regulates pulmonary surfactant homeostasis and alveolar macrophage-mediated innate host defense. Annu Rev Physiol 2002, 64:775-802.

11. Dranoff G, Crawford AD, Sadelain M, Ream B, Rashid A, Bronson RT, et al: Involvement of granulocyte-macrophage colony-stimulating factor in pulmonary homeostasis. Science 1994, 264:713-716.

12. Dranoff G, Mulligan RC: Activities of granulocyte-macrophage colonystimulating factor revealed by gene transfer and gene knockout studies. Stem Cells 1994, 12(Suppl 1):173-182.

13. Kitamura T, Tanaka N, Watanabe J, Uchida K, Kanegasaki S, Yamada Y, et al: Idiopathic pulmonary alveolar proteinosis as an autoimmune disease with neutralizing antibody against granulocyte/macrophage colonystimulating factor. J Exp Med 1999, 190:875-880.

14. Trapnell BC, Whitsett JA, Nakata K: Pulmonary alveolar proteinosis. N Engl J Med 2003, 349:2527-2539.

15. Reed JA, Ikegami M, Cianciolo ER, Lu W, Cho PS, Hull W, et al: Aerosolized GM-CSF ameliorates pulmonary alveolar proteinosis in GM-CSF-deficient mice. Am J Physiol 1999, 276:L556-L563.

16. Bonfield TL, Barna BP, John N, Malur A, Culver DA, Kavuru MS, et al: Suppression of activin $A$ in autoimmune lung disease associated with anti-GM-CSF. J Autoimmun 2006, 26:37-41.

17. Bonfield TL, Raychaudhuri B, Malur A, Abraham S, Trapnell BC, Kavuru MS, et al: PU.1 regulation of human alveolar macrophage differentiation requires granulocyte-macrophage colony-stimulating factor. Am J Physiol Lung Cell Mol Physiol 2003, 285:L1132-L1136.

18. Pascual G, Fong AL, Ogawa S, Gamliel A, Li AC, Perissi V, et al: A SUMOylation-dependent pathway mediates transrepression of inflammatory response genes by PPAR-[gamma]. Nature 2005, 437:759-763. 
19. Glass CK, Saijo K: Nuclear receptor transrepression pathways that regulate inflammation in macrophages and T cells. Nat Rev Immunol 2010, 10:365-376

20. Thomassen MJ, Barna BP, Malur A, Bonfield TL, Farver CF, Malur A, et al: ABCG1 is deficient in alveolar macrophages of GM-CSF knock-out mice and patients with pulmonary alveolar proteinsosis. J Lipid Res 2007, 48:2762-2768.

21. Mather JP: Follistatins and alpha 2-macroglobulin are soluble binding proteins for inhibin and activin. Horm Res 1996, 45:207-210.

22. Shibata Y, Berclaz YP, Chroneos ZC, Yoshida M, Whitsett JA, Trapnell BC: GM-CSF regulates alveolar macrophage differentiation and innate immunity in the lung through PU.1. Immunity 2001, 15:557-567.

23. Su YC, Rolph MS, Hansbro NG, Mackay CR, Sewell WA: Granulocytemacrophage colony-stimulating factor is required for bronchial eosinophilia in a murine model of allergic airway inflammation. J Immunol 2008, 180:2600-2607.

24. Weigert J, Neumeier M, Wanninger J, Schober F, Sporrer D, Weber M, et al: Adiponectin upregulates monocytic activin $A$ but systemic levels are not altered in obesity or type 2 diabetes. Cytokine 2009, 45:86-91.

25. Malur A, Mccoy AJ, Arce S, Barna BP, Kavuru MS, Malur AG, et al: Deletion of PPARY in alveolar macrophages is associated with a Th-1 pulmonary inflammatory response. J Immunol 2009, 182:5816-5822.

26. Bonfield TL, Thomassen MJ, Farver CF, Abraham S, Koloze MT, Zhang X, et al: Peroxisome proliferator-activated receptor-\{gamma\} regulates the expression of alveolar macrophage macrophage colony-stimulating factor. J Immunol 2008, 181:235-242.

27. Sierra-Filardi E, Puig-Kroger A, Blanco FJ, Nieto C, Bragado R, Palomero MI, et al: Activin A skews macrophage polarization by promoting a proinflammatory phenotype and inhibiting the acquisition of antiinflammatory macrophage markers. Blood 2011, 117:5092-5101.

28. Thomassen MJ, Raychaudhuri B, Bonfield TL, Malur A, Abraham S, Barna BP et al: Elevated IL-10 inhibits GM-CSF synthesis in pulmonary alveolar proteinosis. Autoimmunity 2003, 36:285-290.

29. Thomassen MJ, Yi T, Raychaudhuri B, Malur A, Kavuru MS: Pulmonary alveolar proteinosis is a disease of decreased availability of GM-CSF rather than an intrinsic cellular defect. Clin Immunol 2000, 95:85-92.

30. Bonfield TL, Russell D, Burgess S, Malur A, Kavuru MS, Thomassen MJ: Autoantibodies against granulocyte macrophage colony-stimulating factor are diagnostic for pulmonary alveolar proteinosis. Am J Respir Cell Mol Biol 2002, 27:481-486.

31. Bonfield TL, Farver CF, Barna BP, Malur A, Abraham S, Raychaudhuri B, et al: Peroxisome proliferator-activated receptor-gamma is deficient in alveolar macrophages from patients with alveolar proteinosis. Am $J$ Respir Cell Mol Biol 2003, 29:677-682.

32. Bonfield TL, John N, Malur A, Barna BP, Culver DA, Kavuru MS, et al: Elevated monocyte chemotactic proteins 1, 2, and 3 in pulmonary alveolar proteinosis are associated with chemokine receptor suppression. Clin Immunol 2005, 114:79-85.

33. Bonfield TL, Swaisgood CM, Barna BP, Kavuru MS, Thomassen MJ: Elevated gelatinous activity in pulmonary alveolar proteinosis: role of macrophage-colony stimulating factor. J Leukoc Biol 2006, 79:133-139.

34. Ricote M, Huang JT, Welch JS, Glass CK: The peroxisome proliferatoractivated receptor- $\gamma$ (PPAR $\gamma$ ) as a regulator of monocyte/macrophage function. J Leukoc Biol 1999, 66:733-739.

35. Mosser DM, Edwards JP: Exploring the full spectrum of macrophage activation. Nat Rev Immunol 2008, 8:958-969.

36. Gordon S, Martinez FO: Alternative activation of macrophages: mechanism and functions. Immunity 2010, 32:593-604.

37. Liu G, Yang H: Modulation of macrophage activation and programming in immunity. J Cell Physiol 2013, 228:502-512.

38. Gordon S: Alternative activation of macrophages. Nat Rev Immunol 2003, 3:23-35

39. Sica A, Mantovani A: Macrophage plasticity and polarization: in vivo veritas. J Clin Invest 2012, 122:787-795.

40. Fleetwood AJ, Lawrence T, Hamilton JA, Cook AD: Granulocytemacrophage colony-stimulating factor (CSF) and macrophage CSFdependent macrophage phenotypes display differences in cytokine profiles and transcription factor activities: implications for CSF blockade in inflammation. J Immunol 2007, 178:5245-5252.

41. Chawla A: Control of macrophage activation and function by PPARs. Circ Res 2010, 106:1559-1569.
42. Weidenbusch M, Anders HJ: Tissue microenvironments define and get reinforced by macrophage phenotypes in homeostasis or during inflammation, repair and fibrosis. J Innate Immun 2012, 4:463-477.

43. Malur A, Baker AD, McCoy AJ, Wells G, Barna BP, Kavuru MS, et al: Restoration of PPARgamma reverses lipid accumulation in alveolar macrophages of GM-CSF knockout mice. Am J Physiol Lung Cell Mol Physiol 2011, 300:L73-L80.

44. Livak KJ, Schmittgen TD: Analysis of relative gene expression data using real-time quantitative $P C R$ and the 2(-Delta Delta $C(T)$ ) Method. Methods 2001, 25:402-408.

45. Malur AG, Chattopadhyay S, Maitra RK, Banerjee AK: Inhibition of STAT 1 phosphorylation by human parainfluenza virus type $3 \mathrm{C}$ protein. J Virol 2005, 79:7877-7882.

doi:10.1186/1471-2172-14-41

Cite this article as: Dalrymple et al:: Alveolar macrophages of GM-CSF knockout mice exhibit mixed M1 and M2 phenotypes. BMC Immunology 2013 14:41

\section{Submit your next manuscript to BioMed Central and take full advantage of:}

- Convenient online submission

- Thorough peer review

- No space constraints or color figure charges

- Immediate publication on acceptance

- Inclusion in PubMed, CAS, Scopus and Google Scholar

- Research which is freely available for redistribution 